\title{
MEDIA SOSIAL SEBAGAI SARANA PROMOSI KARYA MUSIK DI ERA INDUSTRI 4.0 (STUDI KASUS PADA BAND SENDAU GURAU DI SEMARANG
}

\section{SOCIAL MEDIA AS A PROMOTION OF MUSIC WORKS IN THE INDUSTRIAL ERA 4.0 (CASE STUDY OF THE SENDAU GURAU BAND IN SEMARANG)}

\author{
Yus Rizal Muhammad ${ }^{1}$; Abdul Rachman²; \\ ${ }^{1}$ Pendidikan Sendratasik Universitas Negeri Semarang, Semarang, Indonesia, \\ 2 Pendidikan Sendratasik Universitas Negeri Semarang, Semarang, Indonesia \\ $\left.{ }^{*}\right) \bowtie$ (e-mail)yusrizalm295@gmail.comㄹ, dulkemplinx@mail.unnes.ac.id²,
}

\begin{abstract}
Abstrak
Perkembangan dan kemajuan teknologi informasi terus meningkat tiap tahunnya, hal ini membuat jumlah pengguna internet atau media sosial semakin tinggi diseluruh Dunia. Kemunculan teknologi digital tersebut membuka peluang di berbagai bidang industri khususnya industri musik, layanan streaming sekarang sudah menjadi sesuatu yang sangat berpengaruh di era industri 4.0. Penelitian ini bertujuan untuk mengetahui dan mengidentifikasi bagaimana penggunaan media sosial sebagai sarana promosi karya musik band Sendau Gurau di era industri 4.0. Penelitian ini menggunakan metode kualitatif dengan pengumpulan data melalui observasi, wawancara, dokumentasi dan studi pustaka. Hasil penelitian menunjukan bahwa grup band Sendau Gurau melakukan promosi lagunya melalui platform digital YouTube dan media sosial lainnya seperti Instagram, Facebook, Whatsapp yang berkesinambungan sehingga menarik pengguna media sosial untuk menonton hasil karya mereka yang sudah diunggah ke akun YouTube. Dengan strategi promosi tersebut banyak pengguna media sosial yang tertarik menikmati karya musik band Sendau Gurau melalui media sosial maupun live performance.
\end{abstract}

Kata Kunci : Media Sosial, Promosi, Karya Musik, Industri 4.0

\begin{abstract}
The development and progress of information technology continues to increase every year, this makes the number of internet users or social media increasingly high throughout the World. The emergence of digital technology has opened opportunities in various fields of industry, especially the music industry, streaming services have now become something that is very influential in the industrial era 4.0. This study aims to determine and identify how the use of social media as a means of promotion of Sendau Gurau band music in the industrial era 4.0. This research used qualitative methods by collecting data through observation, interviews, documentation and literature study. The results showed that the Sendau Gurau band promoted their songs through the YouTube digital platform and other social media such as Instagram, Facebook, Whatsapp that continuously attracted social media users to watch their work that has been uploaded to a YouTube account. With this promotion strategy, many social media users are interested in enjoying Sendau Gurau band music through social media and live performance.
\end{abstract}

Keywords: Social Media, Promotion, Music Works, Industry 4.0

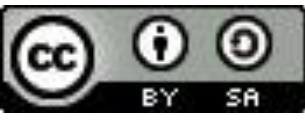




\section{Pendahuluan}

Musik selalu di bicarakan oleh banyak orang karena mengandung banyak keindahan dan fungsi yang bermacam-macam diantaranya sebagai alat komunikasi untuk menyampaikan maksud. Musik merupakan seni yang melukiskan pemikiran dan perasaan manusia yang diekspresika lewat keindahan suara. Dalam kehidupan sehari-hari secara tidak sengaja musik selalu melekat pada kehidupan masyarakat. Bagi musisi banyak hal yang dapat menunjang kreatifitas bermusiknya, dari segi produksi lagu hingga karya musiknya bisa dinikmati dimasyarakat. Tidak hanya sampai membuat karya akan tetapi untuk berhasil didunia industri musik harus didukung dengan prasarana, strategi pemasaran supaya karya musik yang sudah diproduksi bisa dinikmati oleh masyarakat (Iswandi, 2015).

Sejarah berkembangnya media untuk menikmati karya musik dimulai sejak penemuan piringan hitam yang diputar dengan gramophone, kemudian berkembang menjadi kaset pita, berkembang lagi menjadi kepingan compact disk, berubah format $\mathrm{mp3}$ dan akhirnya di era industri 4.0 masyarakat bisa menikmati karya musik melalui streaming platform digital yang sudah tersedia dimedia online, seperti situs Youtube yang menyediakan streaming video musik yang bisa dimanfaatkan para musisi sebagai media promosi. Pada masa lampau sebuah band memasarkan karya musiknya menggunakan compact disk, namun pada era digital pemasaran lebih modern, simple, praktis yaitu dengan menggunakan digital streaming sehingga mudah untuk untuk menikmatinya (Rachman, Abdul; Utomo, 2018; Ramadhani \& Rachman, 2019).

Di era industri 4.0 kemajuan teknologi berkembang pesat yang ditandai dengan adanya perubahan gaya hidup masyarakat. Industri 4.0 adalah transformasi yang demikian cepat dalam desain, manufaktur, operasi, serta layanan produk dan sistem produksi (Alamsyah, 2018). Revolusi industri 4.0 sangat berdampak terhadap kehidupan manusia diseluruh dunia termasuk di Indonesia. Jika revolusi industri 4.0 ini dikaitkan dengan industri musik, maka industri musik 4.0 ini yang akan menjadi tren strategi pemasaran karya musik lewat media digital atau lewat layanan musik streaming yang terhubung dengan internet. Seperti yang diungkapkan Rachman \& Utomo (2017) tren media sosial sangat berkontribusi dalam mempromosikan suatu produk, event atau informasi apapun musik dengan biaya yang lebih rendah akan tetapi mendapatkan hasil yang signifikan.

Band Sendau Gurau merupakan salah satu band di Semarang berorientasi pada kreatifitas dan kebebasan dalam berkarya. Melihat persaingan industri musik yang sangat ketat di era revolusi industri 4.0 ini band Sendau Gurau sebagai brand baru dengan karakteristik aransemen musik yang segar dan lirik yang jenaka mampu bersaing dengan band-band lain kota Semarang. Hal tersebut tidak lepas dari starategi pemasaran musik di era digital yang mereka lakukan seperti mempublikasikan karya-karya musik lewat sosial media atau pemasaran lewat internet untuk mengikuti tren industri 4.0. Berdasarkan latar belakang masalah di atas peneliti tertarik untuk melakukan penelitian lebih dalam tentang strategi pemasaran yang digunakan oleh grup band Sendau gurau.

\section{Metode}

Penelitian ini menggunakan metode deskriptif kualitatif. Menurut (Moleong, 2007) penelitian kualitatif adalah prosedur penelitian yang menghasilkan data deskriptif berupa kata-kata tertulis atau lisan dari orang-orang dan perilaku yang telah diamati. Teknik pengumpulan data yang digunakan dalam penelitian ini adalah studi Pustaka, observasi, 
wawancara, dan dokumentasi. Teknik pemeriksaan keabsahan data diperiksa dengan metode triangulasi data.

Studi pustaka dilakukan peneliti dengan mempelajari penelitian yang terkait sebagai acuan. Data yang di observasi adalah akun-akun media social band Sendau Gurau. Wawancara dilakukan kepada Hendra Kumbara yaitu personil dan manajer band Sendau Gurau. Studi dokumen dilakukan untuk menggali data sekunder sebagai pembantu data primer.

\section{Hasil dan Pembahasan}

\section{Strategi Pemasaran Karya Musik Band Sendau Gurau di Era Industri 4.0}

Strategi internet marketing merupakan usaha pemasaran yang memanfaatkan jejaring internet sebagai salah satu akses agar masyarakat luas dapat mengetahui dan dapat menikmati produk ataupun jasa yang kita pasarkan. Seperti yang diungkapkan (Yulianto, 2015) Internet marketing adalah kegiatan marketing dengan menggunakan peralatan elektronik yang terhubung dengan internet. Dalam hal ini grup band Sendau Gurau menggunakan strategi internet marketing sebagai salah satu strategi pemasarannya, dengan tujuan agar karya musiknya dapat dinikmati oleh masyarakat luas dengan mudah. Strategi pemasaran yang dilakukan band Sendau Gurau yaitu dengan menggunakan sebuah media yang mempunyai fungsi menyampaikan pesan baik video, gambar, audio. Penggunaan media dalam suatu usaha pemasaran merupakan solusi paling efektif karena segala sesuatu pasti akan membutuhkan alat atau media untuk membantu memudahkan dalam hal aktifitas pemasaran maupun komunikasi. Seperti yang diungkapkan Fadli (2018) untuk mempermudah promosi penjualan pelaku industri kini lebih memilih menggunakan sosial media yang praktis dan efektif.

Beberapa media online yang dianggap efektif oleh grup band Sendau Gurau dalam melakukan strategi pemasarannya yaitu Youtube, Instagram, Facebook, dan Whatsapp. Berberapa media online tersebut digunakan band Sendau Gurau sebagai media sharing berupa video musik secara gratis dan juga menghasilkan income genereting bagi grup band dari hasil upload konten mereka. Kurang lebih dua belas karya lagu yang diunggah grup band Sendau Gurau di Akun Youtubenya berupa video musik, diantaranya adalah seperti yang ditunjukan pada tabel.

Tabel 1. Karya lagu band Sendau Gurau di akun Youtube

\begin{tabular}{|l|l|}
\hline 1 & Kids Jaman Now \\
\hline 2 & Keblondrok \\
\hline 3 & Sosial Media \\
\hline 4 & Bersendau Gurau \\
\hline 5 & Hengpon Jadul \\
\hline 6 & Generasi Micin \\
\hline 7 & $\begin{array}{l}\text { Wajah Ayu Untuk Siapa } \\
\text { (Kampret) }\end{array}$ \\
\hline 8 & Gadis Explore \\
\hline 9 & Mantap Jiwa \\
\hline 10 & Kucinta Luna \\
\hline 11 & Pacar Baru \\
\hline 12 & Polos Itu Mitos \\
\hline
\end{tabular}




\section{Promosi Karya Musik Band Sendau Gurau Melalui Youtube}

Youtube merupakan salah satu layanan dari situs Google yang memfasilitasi penggunanya untuk meng- upload video yang bisa diakses dan dinikmati oleh pengguna Internet dari seluruh dunia secara gratis. (Faiqah et al., 2016). Channel YouTube band Sendau Gurau bisa diakses dengan mengetik kata kunci Sendau Gurau dimana secara otomatis akan muncul di jendela pencarian. Youtube digunakan band Sendau Gurau sebagai media promosi dengan bidikan masyarakat secara luas yaitu anak-anak, remaja, dewasa, bahkan orang tua. Karena utuk berselancar ke youtube tidak dibutuhkan dengan membuat akun terlebih dahulu, dengan demikian semua lapisan masyarakat bisa dengan sangat mudah mengaksesnya.

Media youtube ini digunakan secara maksimal oleh band Sendau Gurau untuk melakukan promosi karya musiknya. Hal itu bisa ditunjukkan dengan banyaknya subscriber, viewers, dan likers di channel youtube band Sendau Gurau. Jumlah subscriber sekitar 1740, viewers di setiap video karya musik rata-rata sepuluh ribu hingga dua puluh ribu.

Channel youtube band Sendau Gurau terdapat beberapa fitur yaitu Home, Videos, Playlists, Community, Channels, dan About. Fitur Home adalah halaman awal channel youtube. Fitur Videos berisi video-video karya musik, vlog bersendau gurau, serta aktivitasaktivitas band Sendau Gurau mulai dari aktivitas pentas, Latihan dan lain-lain. Fitur playlists berisi konten video klip dan live performance lagu-lagu karya band Sendau Gurau. Fitur community berisi video-video yang tergabung dalam komunitas band Sendau Gurau. Fitur channels berisi tentang channel-channel youtube yang terintegrasi dengan channel youtube band Sendau Gurau. Fitur about berisi tentang profil band Sendau Gurau.

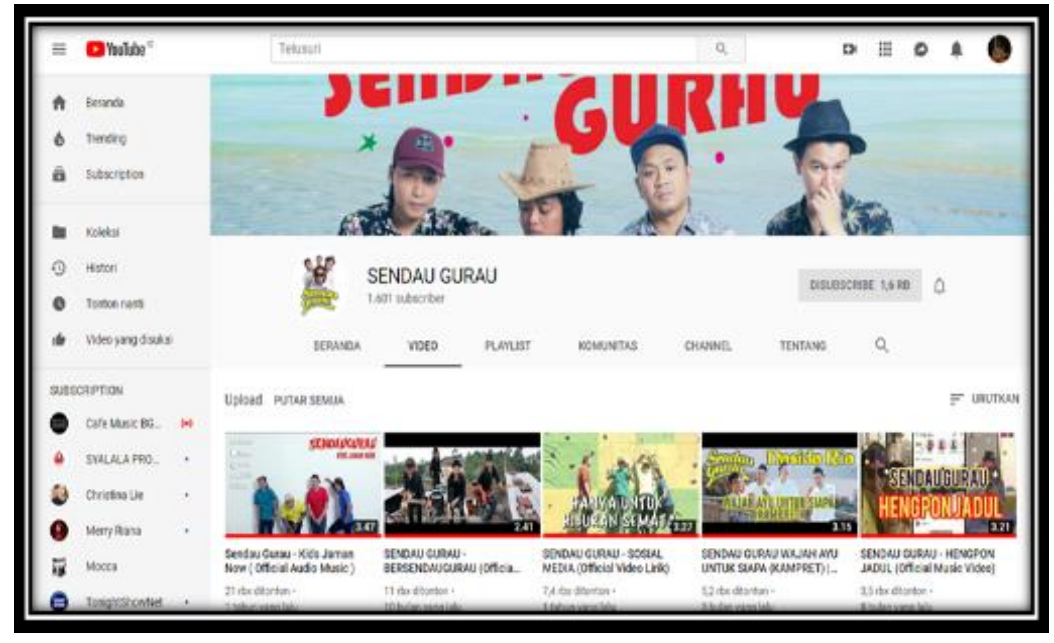

Gambar 1 Akun YouTube Sendau Gurau

Channel youtube ini sangat efektif dalam mempromosikan karya-karya band Sendau Gurau, karena setiap user yang akan menggunakan jasa band Sendau Gurau untuk mengisi sebuah acara tertentu senantiasa menanyakan channel youtube untuk melihat profil dan segala sesuatu tentang band tersebut. Banyaknya karya dan konten yang ada di channel youtube membuat para user yakin akan kompetensi band Sendau Gurau dan berani untuk menggunakan jasanya untuk menyemarakkan sebuah acara. Hal ini sesuai dengan pernyataan Ayesh (2016) bahwa salah satu strategi pemasaran yang bertujuan untuk menarik calon konsumen dengan cara membuat konten-konten yang menarik dan beragam informasi yang dibutuhkan oleh konsumen berupa artikel, video, foto, hasil riset, dan sebagainya. 


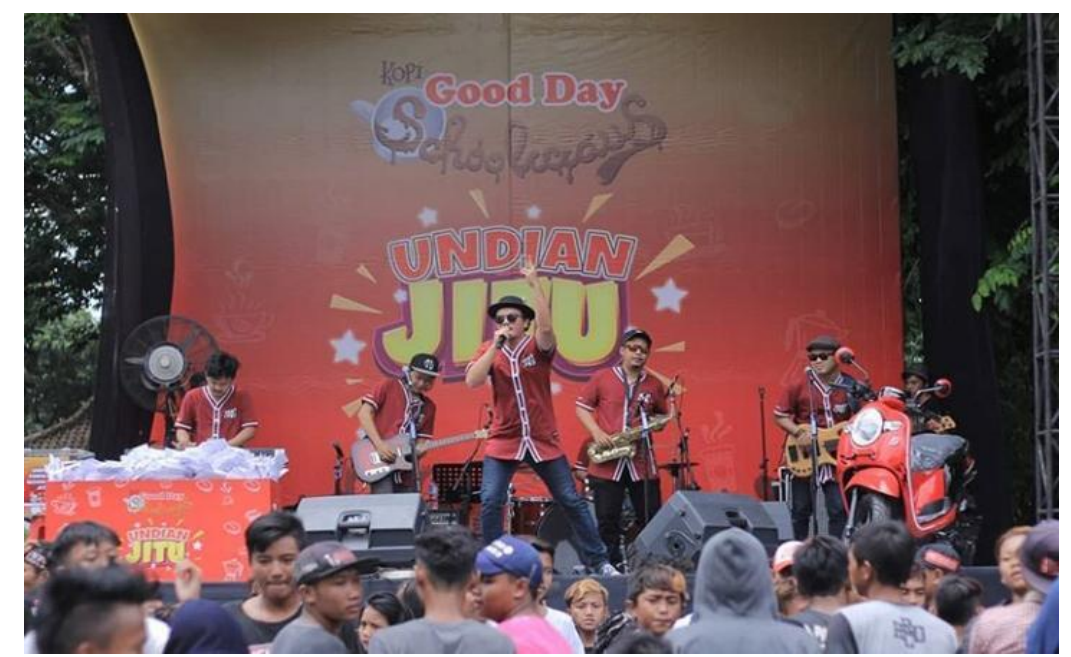

Gambar 2 Live performance band Sendau Gurau pada sebuah acara

\section{Pomosi Karya Musik Band Sendau Gurau Melalui Instagram}

Instagram adalah aplikasi yang memberikan fasilitas berbagi foto maupun video, mengambil foto, menerapkan filter digital, dan membagikannya ke berbagai layanan jejaring sosial, termasuk milik Instagram sendiri (Yasundari, 2016). Akun Instagram digunakan band Sendau Gurau sebagai media promosi dengan bidikan para remaja usia SMP dan SMA karena kebanyakan remaja di usia tersebut sangat aktif dengan akun Instagram. Bisa dibuktikan dengan banyaknya followers, like, dan comment yang sudah mengikuti akun instagram grup band Sendau Gurau. Karya musik dan dan berbagi informasi aktifitas pentas maupun aktifitas sehari-hari berupa cuplikan video yang berdurasi 1 menit atau 15 detik yang diposting melalui insta story dan memiliki fasilitas yang bisa terhubung dengan link akun YouTube.

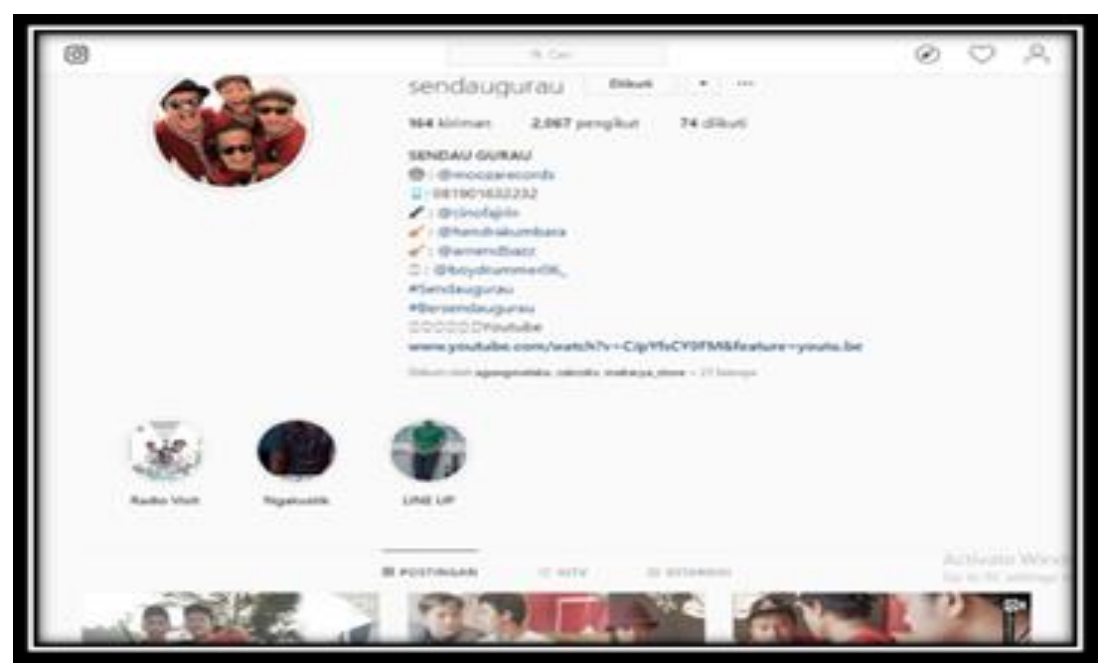

Gambar 3 Akun Instagam Sendau Gurau

Media Instagram ini dirasa cukup efektif dalam rangka mempromosikan karya-karya band Sendau Gurau terutama untuk kalangan remaja usia SMP dan SMA, hal itu bisa ditunjukkan dengan seringnya band Sendau Gurau dipanggil untuk mengisi pentas seni (pensi) di sekolah-sekolah SMP maupun SMA baik di Semarang maupun di luar kota Semarang. 


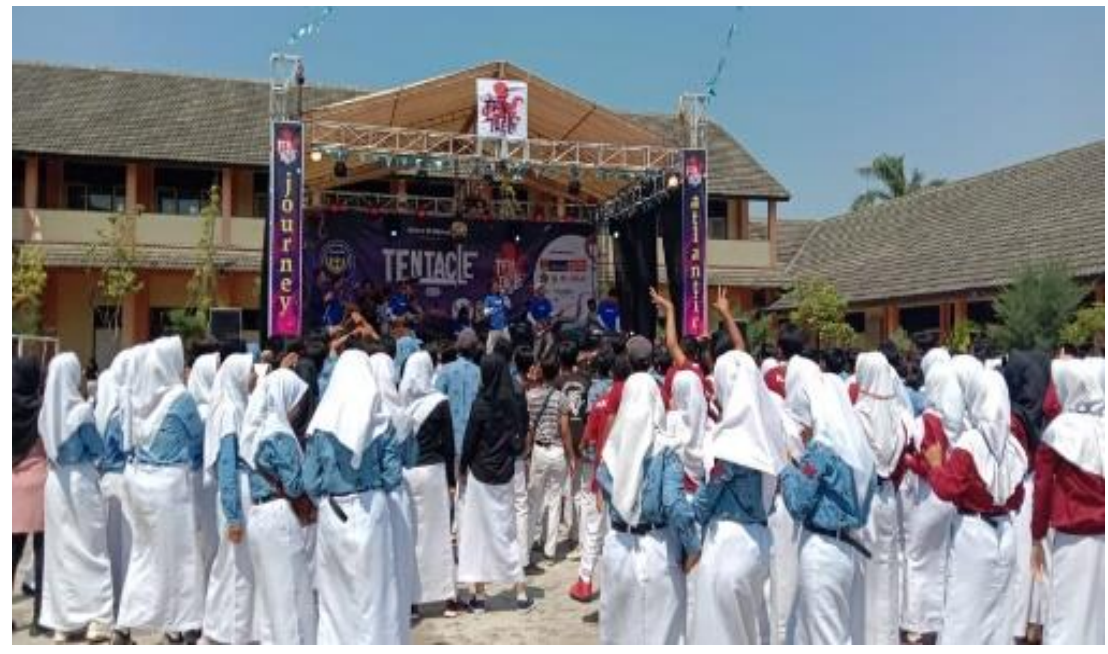

Gambar 4. Live performance band Sendau Gurau pada acara pentas seni di SMA 10 Semarang

\section{Promosi Karya Musik Band Sendau Gurau Melalui Facebook}

Facebook adalah situs jejaring sosial yang memungkinkan pengguna dapat saling berinteraksi dengan pengguna lainnya di seluruh dunia dengan jaringan internet (Tasliman \& Suryawibawa, 2019). Facebook juga memiliki fasilitas untuk mengembangkan bisnis lewat fitur yang sudah disediakan. Hal ini sangat mendukung para pengguna untuk melakukan kegiatan bisnis maupun promosi di platform ini.

Band Sendau Gurau memanfaatkan jejaring sosial facebook untuk meningkatkan eksistensi dan membagikan kegiatan-kegiatan berupa informasi yang dilakukan oleh grup band sendau gurau selama beraktifitas yang berupa foto, video tulisan informasi link YouTube yang merupakan senjata pamungkas untuk media informasi berupa video hasil karya grup band Sendau Gurau. Bidikan promosi melalui akun Facebook ini adalah semua kalangan terutama kaum dewasa, karena kebanyakan pengguna akun facebook adalah kaum dewasa seperti mahasiswa maupun orang-orang yang sudah bekerja.

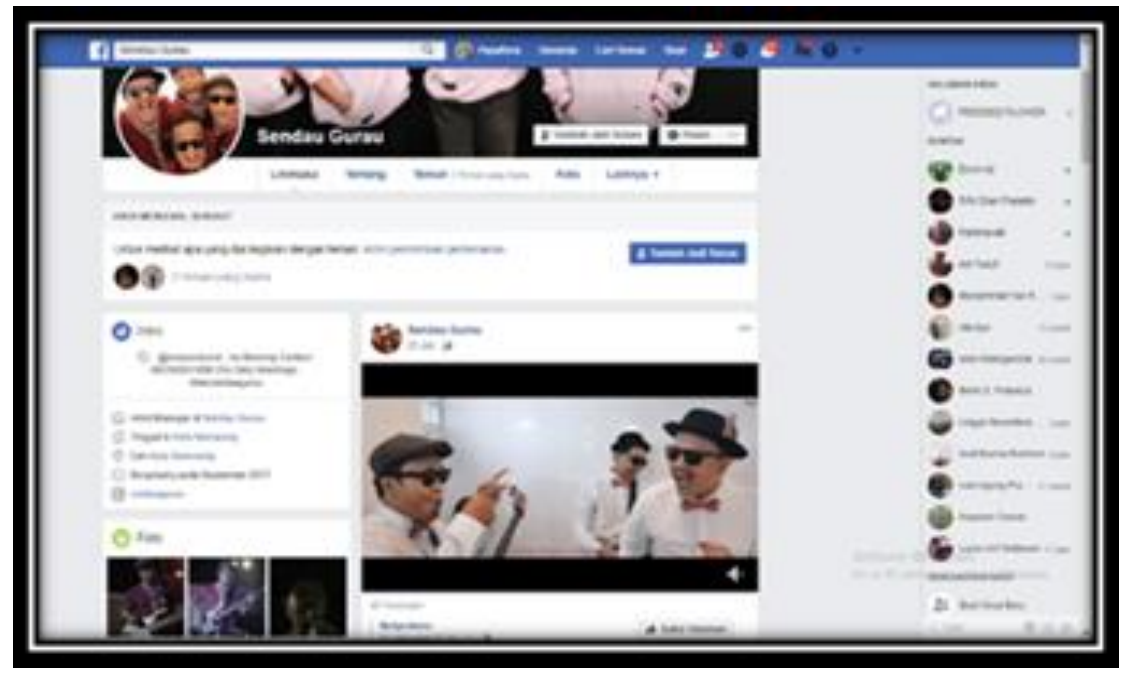

Gambar 5. Akun Facebook Band Sendau Gurau

Penggunaan akun Facebook sebagai media untuk promosi karya musik band Sendau Gurau ini juga tidak kalah efektif, karena dengan promosi via facebook band Sendau Gurau juga sering diundang untuk pentas pada acara-acara kampus maupun acara Lembaga tertentu. 


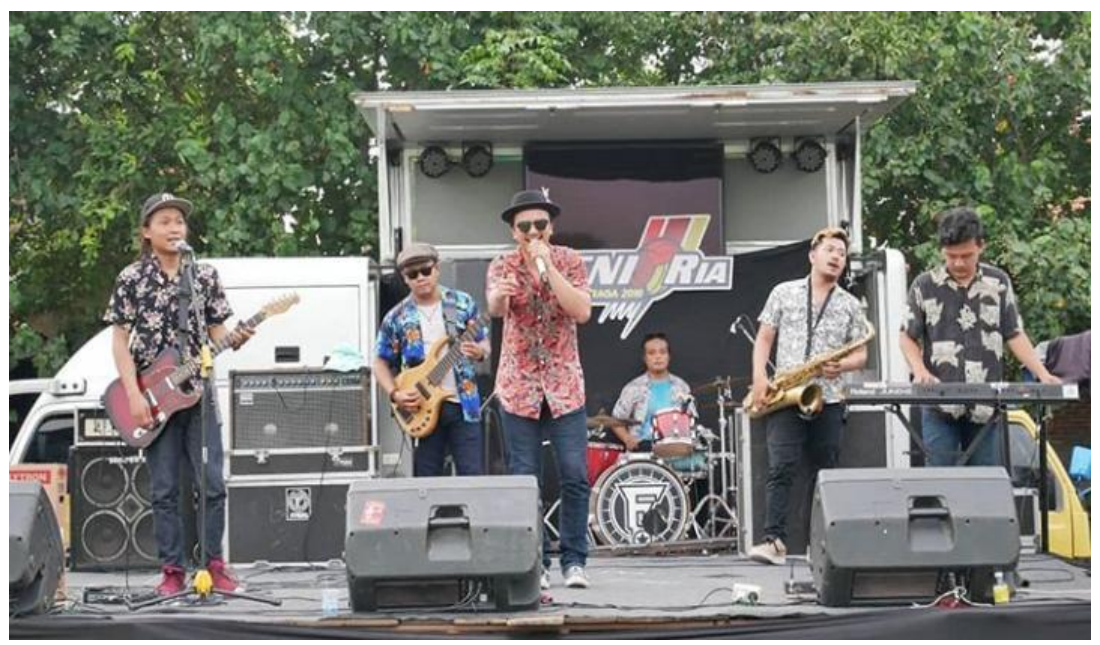

Gambar 6. Live performance band Sendau Gurau pada sebuah acara kampus

\section{Promosi Karya Musik Band Sendau Gurau Melalui Whatsapp}

WhatsApp merupakan salah satu media komunikasi yang dapat di install dalam Smartphone dan dapat digunakan sebagai sarana komunikasi chat berupa pesan teks, gambar, video bahkan telpon, Media ini dapat aktif jika kartu telpon pengguna memiliki paket data internet (Suryadi et al., 2018). Aplikasi whatsapp telah dikenal dan digunakan oleh hampir seluruh lapisan masyarakat, selain mudah dioperasikan whatsapp sangat bermanfaat dan membantu dalam proses berkomunikasi, memberi dan menerima informasi berupa teks, foto, video dan fasilitas lainnya yang sangat menguntungkan bagi penggunanya. Grup band Sendau Gurau memanfaatkan jejaring sosial whatsapp untuk menyebar luaskan informasi yang berkaitan dengan aktivitasnya, dikarenakan whatsapp merupakan aplikasi terpopuler dikalangan masyarakat dalam hitungan detik informasi yang telah diunggah story whatsapp bisa dilihat dan mempengaruhi teman whatsapp yang sudah disimpan nomor kontaknya.

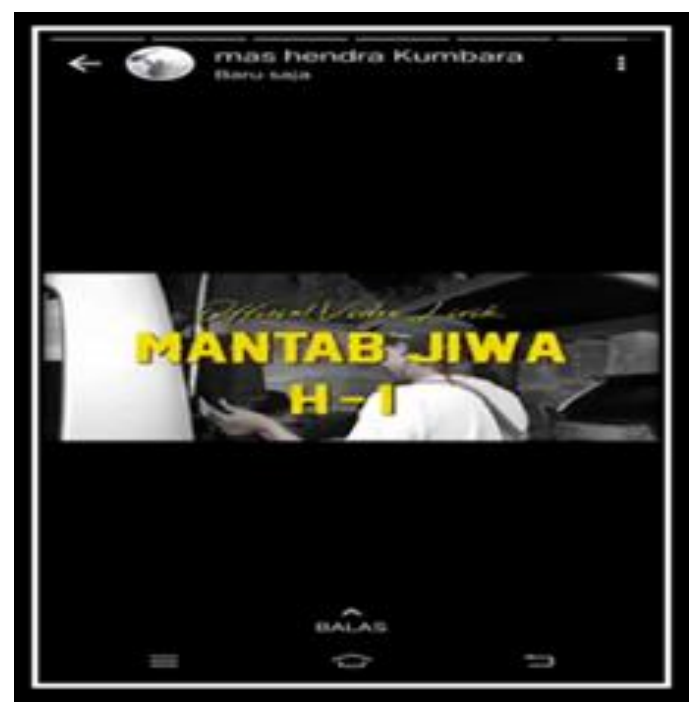

Gambar 7. Akun Whatsapp Band Sendau Gurau

Gambar 7 merupakan hasil screenshot status story dari akun whatsapp Hendra Kumbara salah satu personil grup band Sendau Gurau Semarang, platform digital atau media sosial whatsapp tersbut digunakan sebagai media promosi berupa teks, foto, video, maupun link video youtube yang sudah diunggahnya. 


\section{Kesimpulan}

Berdasarkan hasil dan pembahasan dapat disimpulkan bahwa band Sendau Gurau dalam melakukan promosi hasil karya musiknya di industri 4.0 ini memanfaatkan platform media sosial yang mudah diakses oleh banyak orang yaitu (1) penggunaan media online dalam melakukan promosi seperti YouTube, Facebook, Whatsapp, Instagram (2) konten marketing pembuatan konten untuk bahan promosi yang akan diunggah di media-media sosial (3) mobile marketing pemilihan media sosial yang mudah diakses dengan mudah melalui smartphone yang banyak penggunanya supaya target marketnya sesuai dengan yang sudah direncanakan sehingga tujuan pemasarannya tercapai.

\section{References}

Alamsyah, R. (2018). Analisis Dampak Industri 4.0 terhadap Sistem Pengawasan Ketenaganukliran di Indonesia. Jurnal Forum Nuklir, 12(2)(2), 47-54.

Ayesh, G. (2016). Strategi Internet Marketing Band Indie Pekan Baru Dalam Mempromosikan karya Musik Melalui Reverbnation.Com. JOM FISIP, 3(1), 1-18.

Dewatara, G. W., \& Agustin, S. M. (2019). Pemasaran Musik Pada Era Digital Digitalisasi Industri Musik Dalam Industri 4.0 Di Indonesia. Wacana, 18(1). https://doi.org/10.32509/wacana.v18i1.729

Fadli, R. (2018). Pemanfaatan Media Sosial Instagram Akun @Vapormxpku Dalam Meningkatkan Promosi Penjualan. JOM FISIP, 5, 1-16.

Faiqah, F., Nadjib, M., \& Amir, A. S. (2016). Youtube Sebagai Sarana Komunikasi Bagi Komunitas Makassarvidgram. Jurnal Komunikasi KAREBA, 5(2).

Iswandi. (2015). Refleksi Psikologi Musik Dalam Perilaku Masyarakat Sehari-hari. Humanus, 14(2), 152-157.

Moleong, j, L. (2007). Metode Penelitian Kualitatif. PT. Remaja Rosda Karya Offset.

Rachman, Abdul; Utomo, U. (2018). "SING PENTING KERONCONG": SEBUAH INOVASI PETUNJUKKAN MUSIK KERONCONG DI SEMARANG. JPKS: Jurnal Pendidikan Dan Kajian Seni, 3(1).

Rachman, A., \& Utomo, U. (2018). "Sing Penting Keroncong": Sebuah Inovasi Pertunjukkan Musik Keroncong di Semarang. Jurnal Pendidikan Dan Kajian Seni, 3(1).

Ramadhani, F. A., \& Rachman, A. (2019). Resistensi Musik Keroncong di Era Disrupsi: Studi Kasus pada O.K Gita Puspita di Kabupaten Tegal. Musikolastika: Jurnal Pertunjukan Dan Pendidikan Musik, 1(1), 41-51.

Suryadi, E., Ginanjar, M. H., \& Priyatna, M. (2018). Penggunaan Sosial Media Whatsapp dan Pengaruhnya Terhadap Disiplin belajar peserta Didik Mata Pelajaran Pendidikan Agama Islam. Jurnal Pendidikan Islam, 07. https://doi.org/10.30868/EI.V7

Tasliman, M., \& Suryawibawa, D. T. (2019). Analisis Pemanfaatan Facebook Sebagai Media Promosi Produk Perumahan Syariah di PT. Jannata Land. Prosiding, 940-945.

Yasundari. (2016). Hubungan Penggunaan Instagram Dengan Motivasi Wirausaha Pebisnis Daring (Online) Dalam Meningkatkan Produktivitas. Jurnal Kajian Komunikasi, 4, 208218.

Yulianto, A. (2015). KAJIAN INTERNET MARKETING SEBAGAI SALAH SATU MEDIA. Jurnal Khasanah IImu, VI(1), 65-78. 